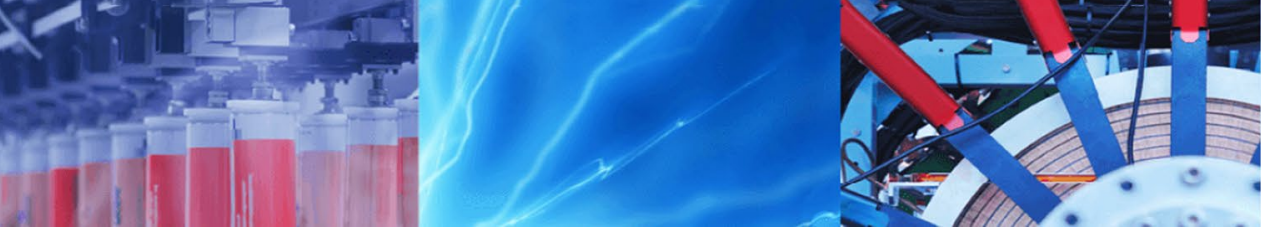

Research Article

\title{
Role of hydroxyl radical scavenger agents in preparing silver nanoparticles under $\gamma$-irradiation
}

\author{
Ekoko Bakambo Gracien ${ }^{1} \cdot$ Muswema Lunguya Jérémie ${ }^{1}$ Lobo Kanza-Kanza Joseph ${ }^{1} \cdot$ Mvele Muamba Omer $^{1}$. \\ Mbongo Kimpanza Antoine ${ }^{1} \cdot$ Kalele Mulonda Hercule $^{1} \cdot$ Mata Niasa Gerard $^{1}$
}

(c) Springer Nature Switzerland AG 2019

\begin{abstract}
In the present work, silver nanoparticles $\left(\mathrm{Ag}^{0}\right)$ were synthesized under $\mathrm{\gamma}$-irradiation from silver nitrate $\left(\mathrm{AgNO}_{3}\right)$ precursor salt, at room temperature in aqeous medium without adding any kind of catalyst. When aqueous solution of $\mathrm{AgNO}_{3}$, the surfactant poly vinyl alcohol and the isopropanol (or formic acid), which were used as hydroxyl oxidative radical scavengers agents were exposed to $\gamma$ rays, $\mathrm{Ag}^{+}$ions were reduced to metallic $\mathrm{Ag}^{0}$ by reactive organic radicals generated under irradiation. When using 2-propanol as free $\mathrm{OH}^{*}$ radical scavenger in polyvinyl alcohol, which prevents $\mathrm{Ag}^{0}$ from aggregation, densely dispersed silver nanoparticles coalesce to give $15 \mathrm{~nm}$ sized silver nanoparticles. The use of formic acid as free $\mathrm{OH}^{*}$ radical scavenger leads to the production of $32 \mathrm{~nm}$ sized metallic nanoparticles. The effects of hydroxyl oxidative radical scavengers agents on the morphology and the size of produced silver nanoparticles were investigated.
\end{abstract}

Keywords $\gamma$-Irradiation method · Silver nanoparticles · Nucleation · Scavengers agents

\section{Introduction}

Metal nanoparticles have drawn recently extensive attentions to many researchers owing to their remarkable physical and chemical properties relative to their macro scale solid counterparts. Silver nanoparticles have exceptional properties and are generously used in medicine (antibacterial properties), in electronics, in optical biosensors, and in catalysis [1-4].

The silver nanoparticles agglomerate rapidly and consequently are short lived species in aqueous solution. A preparation method is than required to avoid the particles agglomeration and then to stabilize silver nanoparticles with non-toxic surfactants. [5-8].

Most of the available fabrication techniques of the silver colloids are based on reduction of ionic silver precursor in aqueous solution in the presence of a surfactant. The most commonly used techniques are chemical reduction [9], sonochemical route $[10,11]$, and thermolysis [12].
The radiolytic reduction has been proven to be a powerful tool to produce monosized and highly dispersed metallic clusters. The metallic nanoparticles can be prepared in an aqueous solution in the presence of a stabilizer without using chemical reducing agents.

The radiolytic synthesis method offers some profitability over the conventional methods because it can be carried out at ambient pressure and room temperature with high reproducibility and it provides fully reduced and highly pure nanoparticles free from by-products or chemical reducing agents. The method is able of controlling the particle size and structure which is influenced by certain parameters such as the choice of solvents and stabilizer, the precursor to stabilizer ratio, $\mathrm{pH}$ during synthesis, and absorbed dose $[4,5,14,15]$.

The radiolytic method is suitable for generation of metal particles, particularly silver, in solution. The amount of zero valent nuclei can be controlled by varying the dose of the irradiation.

Ekoko Bakambo Gracien, profekokob@yahoo.fr | 'Department of Chemistry, Faculty of Science, University of Kinshasa, P.O. Box 190, KIN $\mathrm{XI}$, Kinshasa, Democratic Republic of the Congo.

SN Applied Sciences (2019) 1:961 | https://doi.org/10.1007/s42452-019-0973-7

Received: 5 April 2019 / Accepted: 22 July 2019 / Published online: 2 August 2019 
In this method, the aqueous solution of metal salt is exposed to $\mathrm{Y}$-rays; the transient species namely hydrated electron $\left(\mathrm{e}_{\mathrm{aq}}^{-}\right)$and hydrogen atoms $\left(\mathrm{H}^{\circ}\right)$ arising from radiolysis of water (refer to Sect. 3.8) are strong reducing reagents and they reduce the metal ion to zero valent state. Finally these metal atoms get to gather to form metal nanoparticles in presence of a capping agent, such as polymers, ligands, surfactants etc. The ${ }^{\circ} \mathrm{OH}$ radical (arising from radiolysis of water) being oxidizing in nature can oxidize back the metal atoms. Hence to scavenge ${ }^{\circ} \mathrm{OH}$ radical, isopropyl alcohol (or formic acid) is added to the system [16]. The reaction products of isopropyl alcohol with $\mathrm{OH}$ radical is isopropyl radical while for formic acid is carbon dioxide anion radical (refer to Sect. 3.8).

In our previous works, $\gamma$-irradiation method has been applied to fabricate iron oxides of different morphologies by controlling the $\mathrm{pH}[6,7,17]$ and the spinel $\mathrm{Co}_{3} \mathrm{O}_{4}$ nanoparticles [18]. We did apply the same technique to successfully prepare zinc sulfide nanocrystalline in a non-aqueous system [8] and the nanocomposite $\left(\mathrm{Cd}_{\mathrm{x}} \mathrm{Zn}_{1-\mathrm{x}}\right) \mathrm{S}$ [19].

In this paper, we report on the synthesis of silver nanoparticles under $\gamma$-irradiation using polyvinyl alcohol as a surfactant in order to avoid the particles agglomeration. The nature of $\mathrm{OH}^{*}$ radical scavenger agents in the synthesis of these particles is also investigated.

This technique could be hopefully for simplifying the experimental process, which is an interesting strategy to construct new catalysts. The process is uncomplicated and uncontaminated, the $\gamma$-ray irradiation is harmless and no undesirable impurities similar to silver oxide are produced.

\section{Experimental}

\subsection{Sample preparation}

Except dodecanethiol (98\% purity) which was purchased from Sigma-Aldrich, all the reagents used in the present investigation were analytical grade with minimum assay 95\% and were purchased from Shanghai Chemical Reagent Co., Shanghai, China. They were used as received, without further purification.

Solutions were prepared by dissolving analytically an amount of $\mathrm{AgNO}_{3}$ in distilled water to produce the colorless solution which is due to the presence of the complex ions $\left[\mathrm{Ag}\left(\mathrm{H}_{2} \mathrm{O}\right)\right]^{+}$.

To improve the yield production of metal nanopowders, isopropyl alcohol (IPA) or formic acid was poured in appropriate proportion into the aqueous solution to act as scavenger for oxidative radicals $\left(\mathrm{OH}^{\circ}\right)$ produced during the radiolysis of water under gamma irradiation [20-22].

Polyvinyl alcohol (PVA) was added as emulsifier to prevent the small particles from coming into close contact
Table 1 Preparation of silver nanometer under gamma irradiation using IPA as free radical $\mathrm{OH}^{*}$ scavenger

\begin{tabular}{lllll}
\hline $\begin{array}{l}\text { Sample } \\
\text { number }\end{array}$ & {$\left[\mathrm{Ag}^{+}\right](\mathrm{mole} / \mathrm{L})$} & PVA (mole/L) & IPA (mole/L) & $\begin{array}{l}\text { Irradiation } \\
\text { dose }(\mathrm{kGy})\end{array}$ \\
\hline 1 & 0.05 & 0.20 & 4.0 & 11 \\
2 & 0.10 & 0.20 & 4.0 & 11 \\
3 & 0.05 & 0.20 & 4.0 & 20 \\
4 & 0.10 & 0.20 & 4.0 & 20 \\
5 & 0.10 & 0.20 & 6.0 & 20 \\
6 & 0.10 & 0.20 & 4.0 & 30 \\
7 & 0.10 & 0.20 & 6.0 & 30 \\
\hline
\end{tabular}

Table 2 Preparartion of silver nanometer using formic acid as free radical $\mathrm{OH}^{\cdot}$ scavenger

\begin{tabular}{lllll}
\hline $\begin{array}{l}\text { Sample } \\
\text { number }\end{array}$ & {$\left[\mathrm{Ag}^{+}\right](\mathrm{mole} / \mathrm{L})$} & PVA (mole/L) & $\begin{array}{l}\mathrm{HCOOH} \\
(\mathrm{mole} / \mathrm{L})\end{array}$ & $\begin{array}{l}\text { Irradiation } \\
\text { dose }(\mathrm{kGy})\end{array}$ \\
\hline 1 & 0.05 & 0.20 & 4.0 & 11 \\
2 & 0.10 & 0.20 & 4.0 & 11 \\
3 & 0.05 & 0.20 & 4.0 & 20 \\
4 & 0.10 & 0.20 & 4.0 & 20 \\
5 & 0.10 & 0.20 & 6.0 & 20 \\
6 & 0.10 & 0.20 & 4.0 & 30 \\
7 & 0.10 & 0.20 & 6.0 & 30 \\
\hline
\end{tabular}

and undergoing further aggregation. Indeed, PVA molecules play the role of protective layer to favour metal production reaction by adhering to the surface of silver nanoparticles. The solutions were mixed through magnetic stirrer till they became homogenized. The prepared solutions were kept in a dark to avoid the photoreduction of silver nitrate.

To measure the radiation dose as well as the dose rate delivered to the precursor metal ion solution, the dosimetry of gamma irradiator was measured by Fricke dosimetry and was found to be $1.2 \mathrm{kGy} \mathrm{h}^{-1}$. The mixed solution was irradiated in the field of ${ }^{60} \mathrm{Co}$-irradiator of 325,000 curies activity at different doses with a fixed dose rate of approximately $1.2 \mathrm{kGy} / \mathrm{h}$.

In this experiment, the total irradiation dose was controlled by varying irradiation time (Concentration of reagents used in synthesis procedure are detailed in Tables 1 and 2).

After irradiation, the solution's color absolutely changes. Before irradiation the solutions were colorless, but after irradiation the solution turned colloidal and dark gray in colour, which suggested the formation of silver nanoparticles. Silver nanoparticles in suspension were capped by using $\mathrm{n}$-dodecanethiol $\mathrm{C}_{12} \mathrm{H}_{25} \mathrm{SH}$, which is an organic ligand that electronically and chemically passivates the 
nanocrystal surfaces and prevents uncontrolled particles aggregation. This ligand provides a strong steric barrier for dispersing the nanoparticle [23-25]. The solutions were kept for several hours to allow the silver precipitation. The precipitate was isolated by centrifugation. All the remainder PVA and $n$-dodecylmercaptan were removed by threefold, washing with absolute alcohol and nanoparticles were separated by filtration. After dried in a vacuum furnace at $60^{\circ} \mathrm{C}$ for $7 \mathrm{~h}$, black silver nanoparticles powders were obtained and characterized.

\subsection{Characterization techniques}

The structure and the phase identification of the prepared metal were carried out on X-ray powder diffraction (XRD) patterns, using a D/MAX-2550 Xray diffractometer with $\mathrm{Cu}$-Ka radiation $(\lambda=1.54056 \AA)$ with a nickel filter (Rigaku Co., Japan). The crystalline sizes were calculated by using the Debye-Scherrer formula. The chemical bondings in silver metal were recorded by Fourier transform infrared spectra (SHIMADZU Spectrophotometer) using $\mathrm{KBr}$ pellet technique in the range from 4000 to $400 \mathrm{~cm}^{-1}$ (spectral resolution at $4 \mathrm{~cm}^{-1}$ and number of scans at 20). The surface morphology, size of particles and elemental composition of the prepared material were carried out by field emission scanning electron microscopy (FE-SEM; JEOL JSM-6700F) well equipped with an energy dispersive $\mathrm{X}$-ray (EDAX) spectrophotometer and operated at $20 \mathrm{kV}$. The chemical bonding on the composite surface was studied using X-ray photoelectron spectroscopy (XPS), which was performed with a Thermo VG Scientific ESCALAB 250 spectrometer with a monochromatized Al-Ka X-ray source (1486.6 eV energy). Optical absorption measurements of the composites were performed using a UV-Vis spectrophotometer (Perkin Elmer) in $1 \mathrm{~cm}$ cuvettes at range between 400 and $600 \mathrm{~nm}$. A homogeneous suspension in distilled water, obtained through sonication (for $10 \mathrm{~min}$ ) of well dispersed sample in chloroform is used for UV-vis studies. The morphology and the particles size of material were determined by transmission electron microscopy (TEM; Hitachi $\mathrm{H}-800$ ), and selected area electron diffraction (SAED). The TEM micrographs were taken with an accelerating voltage of $200 \mathrm{kV}$ with samples deposited on a carbon coated copper grid. The wavelength of electron in this condition was approximately about $2.5 \times 10^{-12} \mathrm{~m}$ and the camera length was fixed at $170 \mathrm{~cm}$ for the selected area electron diffraction.

\section{Results and discussion}

\subsection{X-ray diffraction studies}

The structure of synthesized silver nanoparticles was investigated by X-Ray Diffraction (XRD) analysis. The dry dark grey-coloured powder prepared at $30 \mathrm{~Gy}$ irradiation (sample 7) was used for XRD analysis. The diffracted intensities were recorded in the $2 \theta$ range from $30^{\circ}$ to $90^{\circ}$.

Fron XRD pattern, all diffraction peaks positioned at $2 \theta$ of $38.3^{\circ}, 44.5^{\circ}, 64.6^{\circ}, 77.7^{\circ}$ and $81.8^{\circ}$ (Fig. 1 a) could be attributed to (111), (200), (220), (311) and (222) crystallographic planes of the Face Centered Cubic (FCC) silver crystals, in agreement with the standard powder diffraction card of Joint Committee on Powder Diffraction Standards (JCPDS), silver JCPDS File No. 04-0783 from ASTM. No obvious other phases (impurities) were found in the XRD patterns. This proves that the as synthesized Ag nanoparticles were pure. The sharpness of peaks indicated the highly crystalline nature of the prepared products. The sharpening of peaks clearly indicates the presence of nanoparticles in the fabricated samples.

In addition, the silver nanocrystalines prepared using formic acid as scavenger had a similar diffraction profile, peaks at $2 \theta$ of $38.36^{\circ}, 44.52^{\circ}$ and $77.81^{\circ}$ (Fig. 1b) could be respectively, assigned to (111), (200), and (311)
Fig. 1 XRD pattern of the dark grey-coloured silver nanoparticles synthesized under gamma irradiation (at a dose of $30 \mathrm{kGy}$ ) with: a IPA and $\mathbf{b}$ formic acid. The various Bragg peaks are followed by corresponding Miller indices. Results were obtained using CuKa radiation $(\lambda=1.54178 \AA)$
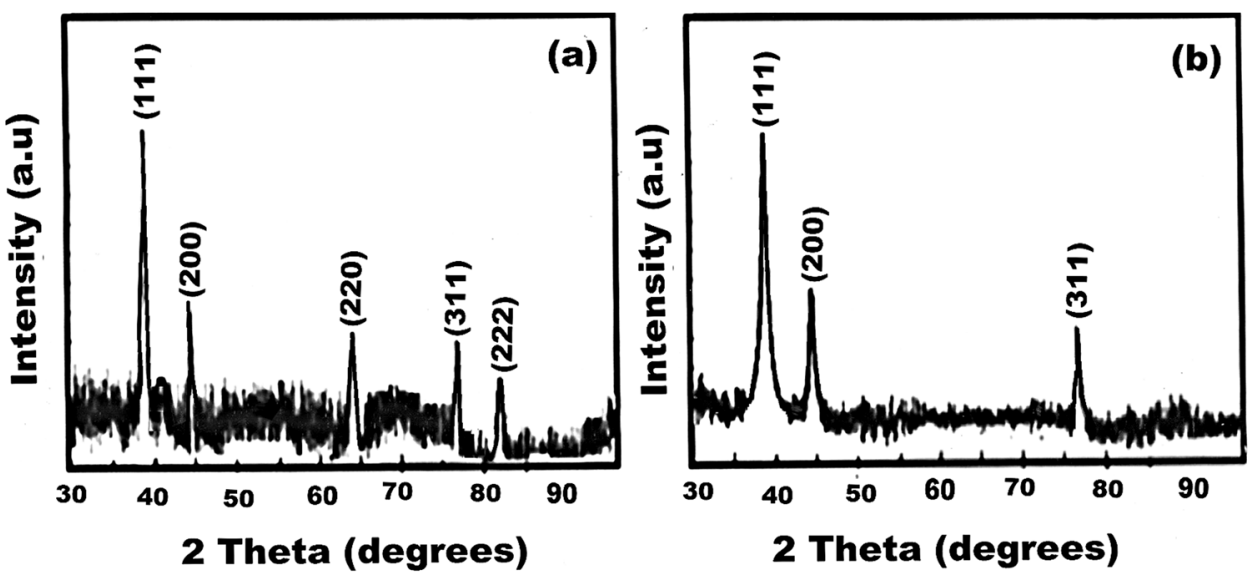
crystallographic planes of the fcc silver crystals. The broadening of peaks indicates the very small sizes of $\mathrm{Ag}$ crystallites.

We noted that when samples are irradiated at low dose of about $11 \mathrm{kGy}$, the XRD patterns (not shown here) indicated some sharp peaks due to unidentified phases, although the main peaks of silver were observed. The intensities of the reflection peaks due to the Ag nano crystallines were in the similar mammer found to increase with the increased Ag crystallites content in several $\gamma$-irradiation doses.

The particle average size of the silver nanoparticles was calculated using Debye-Scherrer's equation $(D=0.92 \lambda / \beta$ $\cos \theta$ ), where, 0.92 is a constant, $\lambda$ is the wavelength of the $X$-rays and $\beta$ is the full width at half maximum (FWHM) of the diffraction peaks and $\theta$ the corresponding diffraction angle in radian.

The calculated average particle size using the main peak (111) was about $32 \mathrm{~nm}$ for the sample synthesized using formic acid as free $\mathrm{OH}^{*}$ radical scavenger. This value was higher than the one calculated from the same peak when using IPA as free $\mathrm{OH}^{*}$ scavenger, where the calculated average particle size was about $15 \mathrm{~nm}$.

\subsection{XPS analysis}

To more endorse the chemical nature of the prepared silver nanopowders, X-ray photoelectron spectroscopy (XPS) was carried out and the result is shown in Fig. 2 . The binding energies were corrected using that for the fortuitous carbon peak at $284.6 \mathrm{eV}$.

As shown in Fig. 2, there are two sharp peaks originating from $\mathrm{Ag} 3 \mathrm{~d}_{5 / 2}$ and $3 \mathrm{~d}_{3 / 2}$, the precedent centered at $368.4 \mathrm{eV}$ and the second at $373.8 \mathrm{eV}$. The peak shape and the peak position of $\mathrm{Ag} 3 \mathrm{~d}_{5 / 2}(368.3 \mathrm{eV})$ are in agreement with those reported for metallic silver $\left(\mathrm{Ag}^{0}\right)$ in the Handbook of X-ray Photoelectron Spectroscopy [26].

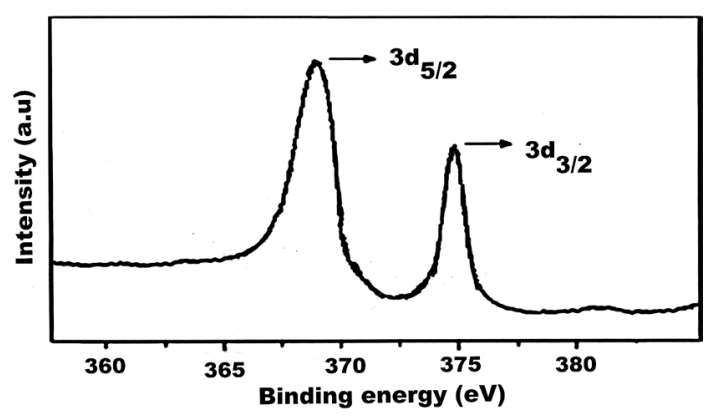

Fig. 2 Ag 3d XPS spectrum for silver nanoparticles prepared under gamma irradiation (at a dose of $30 \mathrm{kGy}$ ) in the presence of IPA; only the region of interest $(355-390 \mathrm{eV})$ is presented
We notice that some trace of PVA as capping agent was detected, which means that under $\gamma$-irradiation, the silver ions are mostly reduced to metallic silver nanoparticles and there is less PVA absorbed physically on the nanosilver surface. Similar result was obtained for the prepared sample in the presence of formic acid.

\subsection{FT-IR spectroscopy analysis}

FT-IR spectroscopy (investigated region: $4000-400 \mathrm{~cm}^{-1}$ ) was carried out in order to ascertain the purity and nature of the prepared metal powders. The FT-IR spectrum of assynthesized Ag nanoparticles is indicated in Fig. 3.

The band which appeared at $3402 \mathrm{~cm}^{-1}$ is attributed to $\mathrm{OH}$ stretching of the polyvinyl alcohol used as capping agent in the preparing silver nanoparticles. The band located at $1635 \mathrm{~cm}^{-1}$ characteristic to the carbonyl group $(C=0)$, represents the strengthening vibration frequently of ketone group. This may indicate oxidation of alcohol group during the irradiation and hence reducing silver ions to metallic silver nanoparticles (according to reaction 14 in Sect. 3.8). The presence of peak located at about $1382 \mathrm{~cm}^{-1}$ can possibly be attributed to the stretching frequency of the nitro functional group and single bond (N-O) from $\mathrm{AgNO}_{3}$, which was used as the silver metal precursor. The peak observed at about $486 \mathrm{~cm}^{-1}$ is mainly attributed to the formation of Ag nanoparticles [27].

\subsection{UV-visible spectroscopy}

The UV-visible absorption spectra of the prepared Ag nanoparticles under $\gamma$-irradiation are shown in Fig. 4, which displays the UV-Visible absorption of the metal as a function of wavelength.

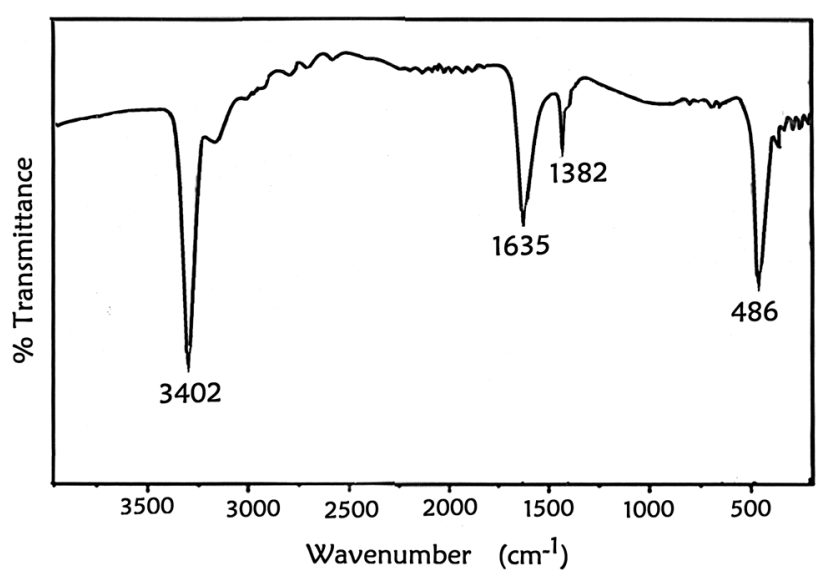

Fig. 3 The FT-IR spectrum of Ag nanoparticles prepared under $\gamma$-irradiation (at a dose of $30 \mathrm{kGy}$ ) in the presence of IPA; only the region of interest $\left(4000-400 \mathrm{~cm}^{-1}\right)$ is presented 


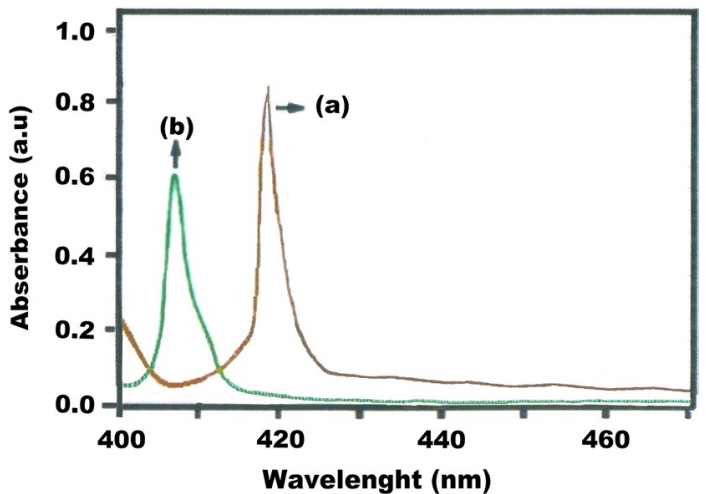

Fig. 4 UV-visible spectrum of Ag nanoparticles synthesized under gamma irradiation (at a dose of $30 \mathrm{kGy}$ ): (a) IPA and Ag dispersed in chloroform (b) formic acid and Ag dispersed in chloroform. Only the region of interest $(400-465 \mathrm{~nm})$ is presented

The characteristic absorption bands detected in the range of about $400-420 \mathrm{~nm}$ are presumably, indicating that there is more formation of silver nanoparticles at higher dose of $\gamma$-irradiation [28]. It is observed that, $\mathrm{Ag}$ nanoparticles dispersed in polar solvent can photoluminesce in the visible region [29-31].

Comparing to the 2-propanol (IPA), when using formic acid, the band absorption peak tended to undergo a blueshift by showing broadest peak at $407 \mathrm{~nm}$ with the lowest intensity than that observed with IPA at $30 \mathrm{kGy}$, which was located at about $417 \mathrm{~nm}$.

The ability to control the size of silver nanoparticles (refer to Fig. 5) is critical since the optical properties of this material largely depend on their size. The UV-visible spectra of the fabricated silver vary correspondingly with their morphology (size). From the UV-visible spectrum, it is noticed that the absorption peak position is sensitive to the size of the prepared particles.

This means the use of formic acid as free $\mathrm{OH}^{\cdot}$ radical scavenger leads to low production of silver nanoparticles and the nanoparticles size distribution is broadened.

A study focuses on a theoretical calculation model of absorption spectra for particles having different sizes which could fit our obtained experimental results is under investigation in our laboratory.

\subsection{Morphology study}

The morphology of silver nanoparticles was studied by transmission electron microscope (TEM). The TEM samples were prepared by first dispersing the dried powder constituted of Ag particles in alcohol (or chloroform) using ultrasonic excitation, then transferring the nanoparticles into the copper grid with carbon support film.
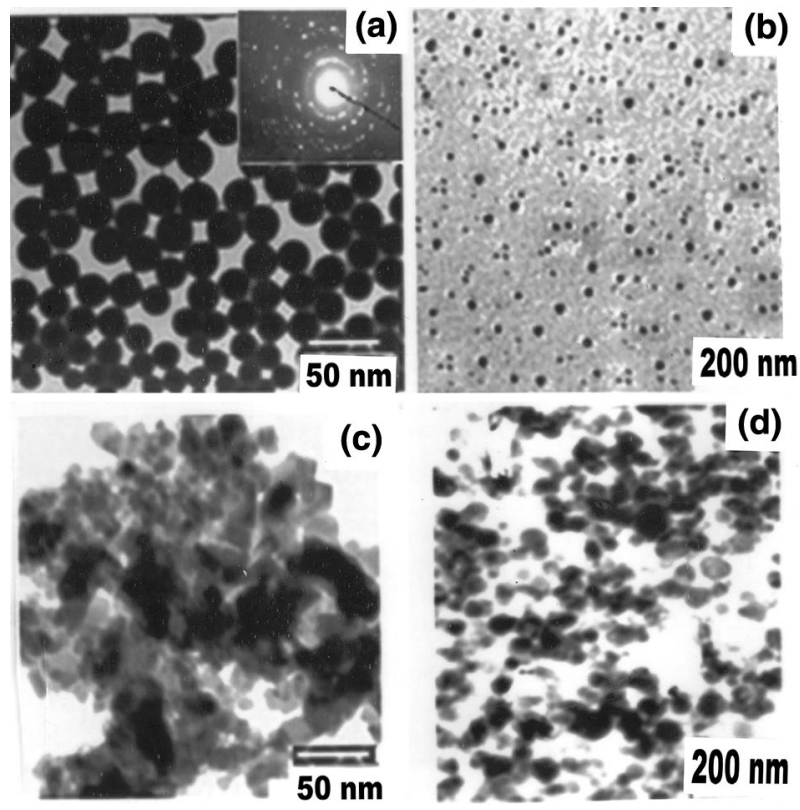

Fig. 5 TEM images of Ag nanoparticles synthesized under gamma irradiation (at a dose of $30 \mathrm{kGy}$ ): a IPA and Ag dispersed in alcohol; b IPA and Ag dispersed in chloroform c formic acid and Ag dispersed in alcohol; $\mathbf{d}$ formic acid and Ag dispersed in chloroform. Only the region of interest $(400-465 \mathrm{~nm})$ is presented

The synthesized silver are consisted of spherical shaped particles with a narrow size distribution ranged from about $10-25 \mathrm{~nm}$ (with an average size of nearly equal to $17 \mathrm{~nm}$ ) when using 2-propanol (refer to Fig. 5a, b) and of about $27-52 \mathrm{~nm}$ (with an average size of about $35 \mathrm{~nm}$ ) when using formic acid (refer to Fig. 5c, d). These observations are also supported by XRD spectrum data.

Figure 5 a shows the selected area diffraction pattern (SAED) of Ag nanoparticles, proving that the particles were well crystallized. The diffraction rings on SAED image matches, with the peaks in XRD pattern which also proves the FCC structure of Ag nanoparticles (calculation not shown here).

TEM images show that under $\gamma$-irradiation, the silver ions $\left(\mathrm{Ag}^{+}\right)$were reduced to silver nanoparticles $\left(\mathrm{Ag}^{0}\right)$ and there was less capping agent absorbed physically on the synthesized metal nanoparticles surface when using IPA.

The results from XRD and TEM demonstrated that under the same conditions, using formic acid in preparing silver by $\mathrm{Y}$-irradiation, the particles diameters increased and agglomeration is observed. When using 2-propanol, the particle sizes decreased abruptly as a result of the induced fragmentation of silver nanoparticles. 


\subsection{Energy dispersive studies (EDS)}

The EDS analysis of the prepared Ag nanopowders was carried out by using internal standard at energy from 0 to $7 \mathrm{keV}$. Energy dispersive X-ray spectroscopy (EDS) spectrum of the fabricated nanopowders is shown in Fig. 6, which revealed that the optical absorption peak was observed around $3 \mathrm{keV}$, which characteristic of metallic silver in the synthesized sample [32]. The prepared powder has mainly silver element and a small amount of carbon was detected in the spectrum (due to the polyvinyl alcohol used as caping agent in the preparing silver nanoparticles). It is confirmed that the silver was pure. Similar result (not shown here) was obtained for the prepared sample under gamma irradiation (at a dose of $30 \mathrm{kGy}$ ) in the presence of formic acid. It confirms the hypothesis of mono crystallinity. The EDX spectrum supports others characterization techniques.

\subsection{Thermal analysis}

It is well known that the Differential Scanning Calorimeter (DSC) is used to determine the phase transitions, glass transition temperatures $(\mathrm{Tg})$ and melting parameters (melting point $\mathrm{Tm}$, thermal decomposition temperature $\mathrm{Td})$.

Thermal analysis of the dried powder obtained after $\gamma$-irradiation were investigated by Differential Scanning Calorimeter (Netzsch STA 409 PG/PC DSC) over a temperature range of $50-350^{\circ} \mathrm{C}$ in ambient air to find out about the silver nanoparticles melting point (Fig. 7).

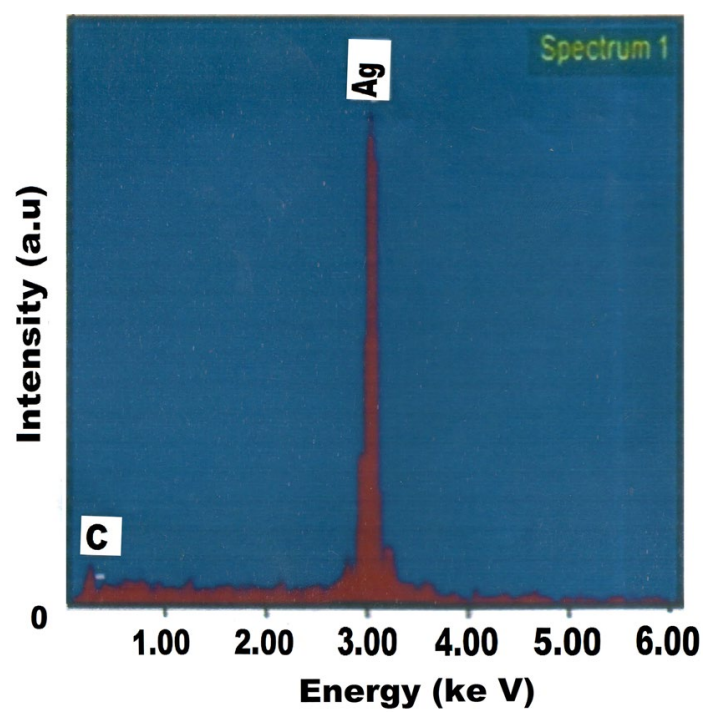

Fig. 6 EDX spectra of Ag nanoparticles prepared under gamma irradiation (at a dose of $30 \mathrm{kGy}$ ) in the presence of IPA; only the region of interest $(0-6 \mathrm{keV})$ is presented

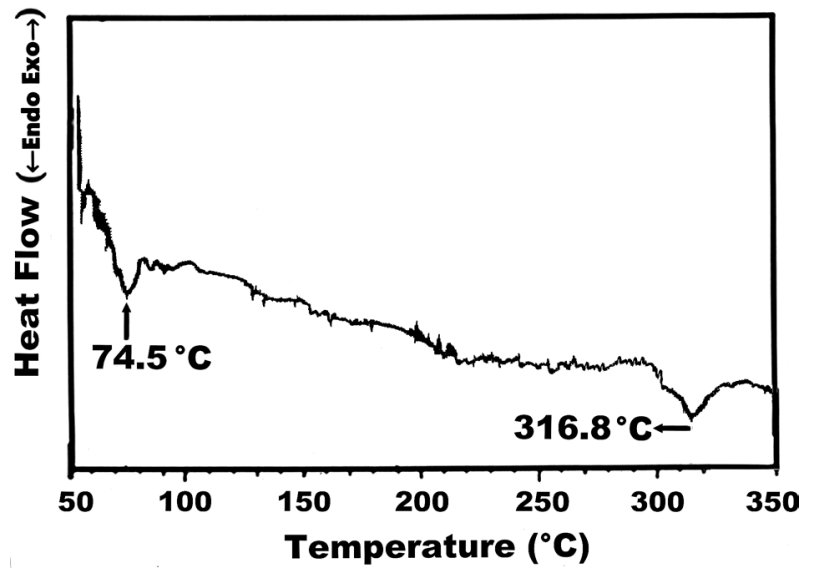

Fig. 7 differential scanning calorimeter curve of silver nanoparticles prepared under gamma irradiation (at a dose of $30 \mathrm{kGy}$ ) with IPA; only the region of interest $\left(50-350^{\circ} \mathrm{C}\right)$ is presented

Figure 7 shows two main heat flow regions, which gives two peaks in the DSC curve. The first region at a temperature of $50-100^{\circ} \mathrm{C}$, with a small low temperature endothermic peak located at $74.5^{\circ} \mathrm{C}$ due to the evaporation of absorbed water molecules present on the surface of Ag nanoparticles during preparation conditions. The second region around $300-350{ }^{\circ} \mathrm{C}$, with a broad high temperature endothermic peak at $316.8^{\circ} \mathrm{C}$ is attributed to $\mathrm{Ag}$ nanoparticles after being released from the surfactant PVA and the $\mathrm{n}$-dodecanethiol, which was used as an organic ligand. This observation suggests that the PVA-Ag-PVA decomposed completely at $316.8^{\circ} \mathrm{C}$ to release free silver metal nanoparticles. The noticed melting point of silver nanoparticles synthetized under gamma irradiation was lower than the bulk material, which has a melting point of about $961.6^{\circ} \mathrm{C}$ [33]. This is due to the presence of smaller particles size in the prepared nanopowders.

\subsection{Mechanism of radiolytic formation of silver nanoparticles}

It is well known that, the radiolysis of water produces free radicals such as: $\mathrm{e}_{\mathrm{aq}}^{-} \mathrm{H}^{\circ}, \mathrm{OH}^{\circ}$ and $\mathrm{HO}_{2}$ or $\mathrm{O}_{2}^{-}$and molecular products such as $\mathrm{H}_{2}$ and $\mathrm{H}_{2} \mathrm{O}_{2}$ (refer to Eq. 1). It was reported that, hydrated electron, $\mathrm{e}_{\mathrm{aq}}^{-}$and hydrogen radical $\mathrm{H}^{\circ}$ are strong reducing species with redox potentials of $\mathrm{E}^{0}$ $\left(\mathrm{H}_{2} \mathrm{O} / \mathrm{e}_{\mathrm{aq}}^{-}\right)=-2.87 \mathrm{~V}$ and and $\mathrm{E}^{0}\left(\mathrm{H}^{+} / \mathrm{H}^{\cdot}\right)=-2.3 \mathrm{~V}$ and $\mathrm{OH}^{\circ}$, $\mathrm{HO}_{2}, \mathrm{O}_{2}^{-}, \mathrm{H}_{2} \mathrm{O}_{2}$ are oxidizing species with redox potentials of $\mathrm{E}^{0}\left(\mathrm{OH} / \mathrm{H}_{2} \mathrm{O}\right)=+2.8 \mathrm{~V}$. The concentrations of the radiolysis products depend on radiation energy absorption rate, the solution $\mathrm{pH}$, and temperature [34].

$\mathrm{H}_{2} \mathrm{O} \stackrel{\gamma \text {-rays }}{\longrightarrow} \mathrm{H}_{2}, \mathrm{H}_{2} \mathrm{O}_{2}, \mathrm{H}^{*}, \mathrm{HO}^{*}, e_{a q^{\prime}}^{-}, \mathrm{H}_{2} \mathrm{O}^{+}, \mathrm{H}_{2} \mathrm{O}^{*}, \mathrm{HO}_{2}$ 
On one hand, these reducing species can readily interact with dissolved transition metal ions $\left(\mathrm{M}^{+}\right)$to lower their oxidation states.

$\mathrm{M}^{+}+\mathrm{e}_{a q}^{-} \rightarrow M^{0}$

$\mathrm{M}^{+}+\mathrm{H}^{\cdot} \rightarrow \mathrm{M}^{0}+\mathrm{H}^{+}$

This enables any metal ions to be reduced to zero valence metal atoms without using chemical reducing agents. Consequently, this reaction leads to the formation of uniformly dispersed and highly stable nanoparticles without unnecessary by-products.

On the other side, hydroxyl radicals $\left(\mathrm{OH}^{\circ}\right)$, could oxidize the ions or the atoms into a higher oxidation state. To prevent the oxidation of nascent metal clusters, an amount of isopropyl alcohol or formate ions is consequently added into the precursor solutions prior to the irradiation process in order to scavenge $\mathrm{OH}^{\circ}$ and $\mathrm{H}^{\circ}$ free radicals and then convert the scavenger agent into the secondary radicals (hydroxyalkyl radicals), which finally reduce metal ions $\left(\mathrm{M}^{+}\right)$ into atoms $\left(\mathrm{M}^{0}\right)$ : [13]

$\mathrm{OH}^{\bullet}+\mathrm{CH}_{3} \mathrm{CHOHCH} \mathrm{H}_{3} \rightarrow \mathrm{H}_{2} \mathrm{O}+\mathrm{H}_{3} \mathrm{CC}^{\cdot} \mathrm{OHCH} \mathrm{CH}_{3}$

$\mathrm{H}^{\bullet}+\mathrm{CH}_{3} \mathrm{CHOHCH} \mathrm{CH}_{3} \rightarrow \mathrm{H}_{2}+\mathrm{H}_{3} \mathrm{CC}^{\cdot} \mathrm{OH} \mathrm{CH}_{3}$

$\mathrm{M}^{+}+\mathrm{H}_{3} \mathrm{CC}^{\cdot} \mathrm{OH} \mathrm{CH}_{3} \rightarrow \mathrm{CH}_{3} \mathrm{COCH}_{3}+\mathrm{M}^{0}+\mathrm{H}^{+}$

With formate ions, there is production of carbon dioxide anion radical $\left(\mathrm{CO}_{2}^{-}\right)$, which is a reducing specie that forms with carbon dioxide a negative redox potential of $\mathrm{E}^{0}\left(\mathrm{CO}_{2} /\right.$ $\left.\mathrm{CO}_{2}^{--}\right)=-2.0 \mathrm{~V}$.

$\mathrm{OH}^{\cdot}+\mathrm{HCO}_{2}^{-} \rightarrow \mathrm{H}_{2} \mathrm{O}+\mathrm{CO}_{2}^{\cdot-}$

$\mathrm{H}^{\bullet}+\mathrm{HCO}_{2}^{-} \rightarrow \mathrm{H}_{2}+\mathrm{CO}_{2}^{\cdot-}$

$\mathrm{M}^{+}+\mathrm{CO}_{2}^{\cdot-} \rightarrow \mathrm{CO}_{2}+\mathrm{M}^{0}$

The released carbon dioxide can react with, hydrated electron, $\mathrm{e}_{\mathrm{aq}}^{-}$to produce more reducing specie as follow:

$\mathrm{CO}_{2}+\mathrm{e}_{\mathrm{aq}}^{-} \rightarrow \mathrm{CO}_{2}^{--}$

The Polyvinyl alcohol (PVA) chain plays a significant role in avoiding the formation of metal hydroxide clusters by hydrolysis of metal ions, thus preventing them from aggregation.

Many active - $\mathrm{OH}$ groups in the structure of the monomere PVA are capable of absorbing metal ions $\left(\mathrm{M}^{+}\right)$through secondary bonds according to the reaction:

$\mathrm{PVA}-\mathrm{OH}+\mathrm{M}^{+} \rightarrow \mathrm{PVA}-\mathrm{O}-\mathrm{M}+\mathrm{H}^{+}$

In the absence of a radical scavenger, ${ }^{\circ} \mathrm{OH}$ radicals in aqueous medium can induce the radiation crosslinking of PVA molecules according to the reactions 12 and 13 [35]:

$\mathrm{PVA}(\mathrm{H})+\mathrm{OH}^{\bullet} \rightarrow \mathrm{PVA}^{\bullet}+\mathrm{H}_{2} \mathrm{O}$
2PVA ${ }^{\circ} \rightarrow$ PVA-PVA (Crosslinked polymer)

The hydroxyl radicals almost exclusively react with PVA and the $\mathrm{Ag}^{+}$ions reduction can take place both by hydrated electrons and the polymeric radicals PVA:

The radiolytic reduction mechanism of silver nitrate aqueous solution to nanosilver by $\gamma$-irradiation technique is accomplished by organic radicals generated under irradiation. IPA (or formic acid) plays an important role in scavenging the free radicals and are converted into organic radicals (refer to Eqs. 4, 5, 7, 8, 10). In this process, $\mathrm{Ag}^{+}$was successfully reduced to form Ag nanoparticles according to reactions proposed following Eqs. (14) and (15)

$\mathrm{Ag}^{+}+\mathrm{H}_{3} \mathrm{CC}^{\circ} \mathrm{OHCH} \rightarrow \mathrm{CH}_{3} \mathrm{COCH}_{3}+\mathrm{Ag}^{0}+\mathrm{H}^{+}$

$\mathrm{Ag}^{+}+\mathrm{CO}_{2}^{--} \rightarrow \mathrm{CO}_{2}+\mathrm{Ag}^{0}$

\section{Conclusion}

Spherical sharped silver nanoparticles were prepared successfully by $\gamma$-radiation technique at room temperature, ambient pressure and without any kind of catalysts, in water system, using PVA as a stabilizer.

It is noticed that under the same conditions, using formic acid the particles diameters increased and agglomeration is observed. When using 2-propanol the particle sizes decreased abruptly as a result of the induced fragmentation of silver nanoparticles.

TEM images show that under $\gamma$-irradiation, the silver ions $\left(\mathrm{Ag}^{+}\right)$were reduced to silver nanoparticles $\left(\mathrm{Ag}^{0}\right)$ and there was less capping agent absorbed physically on the synthesized metal nanoparticles surface when using IPA.

The optical properties of silver nanoparticles largely depend on their size (morphology). From the UV-visible spectrum, it is noticed that the absorption peak position is sensitive to the size of the prepared particles.

Acknowledgements The authors gratefully thank Dr. Xin Lihui of the National Center of Shanghai Institute of Measurement and Testing Technology for his help with SEM, TEM, DSC, FT-IR spectroscopy analysis and XRD analysis, as well as Professor Dr Zhou Ruimin of Shanghai Applied Radiation Institute, Shanghai University, for his support to realize this work.

\section{Compliance with ethical standards}

Conflict of interest The authors declare that they have no conflict of interest.

\section{References}

1. Mishra A, Sardar M (2015) Cellulase assisted synthesis of nanosilver and gold: application as immobilization matrix for biocatalysis. Int J Biol Macromol 77:105-113 
2. Fatemeh $\mathrm{H}$, Hedayatollah $\mathrm{G}$, Azam S (2018) Ultrasensitive optical biosensor for detection of mi-RNA-155 using positively charged Au nanoparticles. Sci Rep 8:2943

3. Vincenzo A, Bahr OM, Francesco S et al (2010) A study of the surface plasmon resonance of silver nanoparticles by the discrete dipole approximation method: effet of shape, size, structure and assembly. Plasmonics 5(1):85-97

4. Hareesh K, Joshi RP, Dahiwale SS et al (2016) Synthesis of Agreduced graphene oxide nanocomposite by gamma radiation assisted method and its photocatalytic activity. Vacuum 124:40-45

5. Pimpon U, Jarurattana E, Theeranan T et al (2015) Radiolytic synthesis of colloidal silver nanoparticles for antibacterial wound dressings. Adv Mater Sci Eng. https://doi. org/10.1155/2015/376082

6. Bakambo EG, Zhou R, Hui XL et al (2006) Effect of $\mathrm{pH}$ on the morphology of iron oxides synthesized under gamma irradiation. J Radiaoanal Nucl Chem 270(2):473-478

7. Bakambo EG, Lobo Joseph K-K, Mvele OM et al (2014) Gamma irradiation inducing the synthesis of magnetic $\mathrm{Fe}_{3} \mathrm{O}_{4}$ nanorod particles in alkaline medium. Int J Mater Sci Appl 3(6):339-343

8. Bakambo EG, Zhou R, Hui XL et al (2005) Synthesis of nanocrystalline zinc sulfide in a non-aqueous system by gamma irradiation. J Radiaoanal Nucl Chem 265(1):3-6

9. Sujuan $Y$, Jingfu L (2015) Silver nanoparticles in the environments. Springer, Berlin

10. Yakoot SM, Salem NA (2016) A sonochemical_assisted simple and green synthesis of silver nanoparticles and its use in cosmetics. Int J Pharmacol 12(5):572-575

11. Fawzi RE, Kamyar S, Mansor B et al (2015) Green sonochemical synthesis of silver nanoparticles at varying concentrations of carrageenan. Nanoscale Res Lett 41(11):8515-8525

12. Mohammad K, Mehdi Z, Bahrami M et al (2015) A thermal decomposition route for the synthesis of silver ribbons. Russ $J$ Appl Chem 88(12):2035-2037

13. Belloni J (2006) Nucleation, growth and properties of nanoclusters studied by radiation chemistry: application to catalysis. Catal Today 113:141-156

14. Soliman YS (2014) Gamma radiation induced synthesis of silver nanoparticles in gelatin and its applications for radiotherapy dose measurements. Radiat Phys Chem 102:60-67

15. El-Batal Al, Haroun BM, Farrag AA et al (2014) Synthesis of silver nanoparticles and incorporation with certain antibiotic using gamma irradiation. Br J Pharm Res 4(11):1341-1363

16. Peng C, Linyong S, Yankuan L et al (2007) Synthesis of silver nanoparticles by $Y$-ray irradiation in acetic water solution containing chitosan. Radiat Phys Chem 76:1165-1168

17. Zhang $X$, Zhou $R$, Rao $W$ et al (2006) Influence of precipitor agents $\mathrm{NaOH}$ and $\mathrm{NH}_{4} \mathrm{OH}$ on the preparation of $\mathrm{Fe}_{2} \mathrm{O}_{3}$ nanoparticles synthesized by electron beam irradiation. J Radioanal Nucl Chem 270(2):285-289

18. Muswema JL, Ekoko GB, Lobo Joseph K-K et al (2019) Gamma radiation induced synthesis of spinel $\mathrm{CO}_{3} \mathrm{O}_{4}$ nanoparticles. SN Appl Sci 1:333. https://doi.org/10.1007/s42452-019-0342-6

19. Bakambo EG, Zhou R, Hui XL et al (2004) Synthesis of nanocomposite $(\mathrm{Cdx}, \mathrm{Zn} 1-\mathrm{x}) \mathrm{S}$ by gamma irradiation in an aqueous solution. J Radiaoanal Nucl Chem 262(3):751-754
20. Verne $L(2000) \mathrm{OH}$ radicals and oxidizing products in the gamma radiolysis of water. Radiat Res 153(2):196-200

21. Minhui X, Xiaogang G, Shuguang L et al (2016) Degradation of carbon tetrachloride in thermally activated persulfate system in the presence of formic acid. Front Environ Sci Eng 10(3):438-446

22. Spinks JWT, Woods RJ (1990) An introduction to radiation chemistry, 3rd edn. Wiley, New York, p 285

23. Ankita S, Bhanu PS, Arvind KG (2014) Synthesis and caracterisation of dodecanethiol-stabilized gold nanoparticles. Indian J Pure Appl Phys 52:93-100

24. Lixin M, Dongzhi L, Wei L et al (2011) Effets of dodecylamine and dodecanethiol on the conductive properties of nano-Ag films. Appl Surf Sci 257(13):5746-5753

25. Danhui Z, Youbo Y (2017) Synthesis of 1-dodecanethiol-capped Ag nanoparticles and their catalytic activity. Appl Phys A 123(1):82-89. https://doi.org/10.1007/s00339-016-0716-1

26. Moulder JF, Stickle WF, Sobol PE et al (1992) Handbook of X-ray photoelectron spectroscop. Perkin- Elmer Corporation, Physical Electronics Division, Waltham

27. Coates J (2000) Encyclopedia of analytical chemistry. In: Meyers RA (ed) Interpretation of infrared spectra, a practical approach. Wiley, Chichester, pp 10815-10837

28. Huanga NM, Radimanb S, Limc HN et al (2009) $Y$-Ray assisted synthesis of silver nanoparticles in chitosan solution and the antibacterial properties. Chem Eng J 155(1-2):499-507

29. Lecoultre S, Rydlo A, Buttet J et al (2011) Ultraviolet-visible absorption of small silver clusters in neon: $\mathrm{Ag}_{\mathrm{n}}(\mathrm{n}=1-9)$. J Chem Phys 134(8):184504-184507

30. Taleb A, Petit C, Pelini MP (1998) Optical properties of selfassembed $2 \mathrm{D}$ and $3 \mathrm{D}$ superlattices of silver nanoparticles. J Phys Chem B 102(12):2214-2220

31. Jingjing W, Claire D, Jean-Luc $P$ et al (2019) Influence of cracks on the optical properties of silver nanocrystals supracrystal films. ACS Nano 13(1):573-581

32. Syed B, Nagendra Prasad MN, Dhananjaya B et al (2016) Synthesis of silver nanoparticles by endosymbiont pseudomonas fluorescens CA 417 and their bactericidal activity. Enzyme and Microbial Technology 95:128-136

33. NCDPI References tables for chemistry, stock no 7952, adopted in 2000

34. Rojas J, Castano C (2012) Production of palladium nanoparticles supported on multiwalled carbon nanotubes by gamma irradiation. Radiat Phys Chem 81:16-21

35. Ulanski $\mathrm{P}$, Bothe $\mathrm{E}$, Rosiak JM et al (1994) OH radical induced crosslinking and strand breakage of poly (vinyl alcohol) in aqueous solution in the absence and presence of oxygen. A pulse radiolysis and product study. Macromol Chem Phys 195:1443-1461

Publisher's Note Springer Nature remains neutral with regard to jurisdictional claims in published maps and institutional affiliations. 